Article

\title{
Experimental Study on Carbonation Durability of Kaolin Strengthened with Slag Portland Cement
}

\author{
Qingbiao Wang ${ }^{1,2,3}$, Yiming Ma ${ }^{1}$, Fuqiang Wang ${ }^{4}$, Zhenyue Shi ${ }^{5, *}{ }^{\circ}$, Hongyue You ${ }^{4}$, Yuanyuan Tian ${ }^{4}$, \\ Yunfei Liu ${ }^{1}$, Zhongjing Hu ${ }^{5}$, Hongxu Song ${ }^{6}$, Dong Wang ${ }^{4}$, Yueqiang Sun ${ }^{1}$, Rongshuai Yang ${ }^{1}$ and Haoran Sun ${ }^{1}$
}

check for updates

Citation: Wang, Q.; Ma, Y.; Wang, F.; Shi, Z.; You, H.; Tian, Y.; Liu, Y.; Hu, Z.; Song, H.; Wang, D.; et al. Experimental Study on Carbonation Durability of Kaolin Strengthened with Slag Portland Cement. Materials 2022, 15, 1240. https://doi.org/ $10.3390 / \mathrm{ma} 15031240$

Academic Editors: Mostafa Seifan and F. Pacheco Torgal

Received: 5 July 2021

Accepted: 3 February 2022

Published: 7 February 2022

Publisher's Note: MDPI stays neutral with regard to jurisdictional claims in published maps and institutional affiliations.

Copyright: (C) 2022 by the authors. Licensee MDPI, Basel, Switzerland. This article is an open access article distributed under the terms and conditions of the Creative Commons Attribution (CC BY) license (https:// creativecommons.org/licenses/by/ $4.0 /)$.
1 College of Resources, Shandong University of Science and Technology, Tai'an 271019, China; skd990748@sdust.edu.cn (Q.W.);202183300045@sdust.edu.cn (Y.M.); 202083300013@sdust.edu.cn (Y.L.) 202083300021@sdust.edu.cn (Y.S.); 202083300026@sdust.edu.cn (R.Y.); 202083300019@sdust.edu.cn (H.S.)

2 State Key Laboratory of Mining Disaster Prevention and Control Co-Founded by Shandong Province and the Ministry of Science and Technology, Shandong University of Science and Technology, Qingdao 266590, China

3 National Engineering Laboratory for Coalmine Backfilling Mining, Shandong University of Science and Technology, Tai'an 271019, China

4 College of Civil Engineering and Architecture, Shandong University of Science and Technology, Qingdao 266590, China; 201983040061@sdust.edu.cn (F.W.); 201982040039@sdust.edu.cn (H.Y.); 201982040032@sdust.edu.cn (Y.T.); 201982040033@sdust.edu.cn (D.W.)

5 College of Safety and Environmental Engineering (College of Safety and Emergency Management), Shandong University of Science and Technology, Qingdao 266590, China; huyang@sdust.edu.cn

6 College of Energy and Mining Engineering, Shandong University of Science and Technology, Qingdao 266590, China; 201983010016@sdust.edu.cn

* Correspondence: 201881010015@sdust.edu.cn

\begin{abstract}
Slag Portland cement is an environmentally friendly and energy-saving product, which is widely used in cement-reinforced soil. This study used slag Portland cement-reinforced soil as the research object and P.O $42.5+$ kaolin (POK) as the reference group. The carbonation depth and strength of P.S.A 42.5 + kaolin (PSK) at different curing times were analyzed using carbonation depth, uniaxial ground pressure strength, scanning electron microscopy (SEM), energy-dispersive spectroscopy (EDS) and X-ray diffraction (XRD). The test results show the following: (1) The active substances in PSK samples can react with calcium hydroxide produced during cement hydration and can reduce the content of $\mathrm{OH}^{-}$. The PSK samples react with $\mathrm{OH}^{-}$and $\mathrm{CO}_{2}$ in the carbonation environment. Both processes considerably reduce the content of $\mathrm{OH}^{-}$. (2) Due to the decrease in $\mathrm{OH}^{-}$content, the carbonation durability of slag Portland cement-reinforced soil is significantly less than that of ordinary Portland cement. (3) The carbonation of slag Portland cement-reinforced soil improves its strength. (4) The results of SEM + EDS and XRD confirm the carbonation depth and strength of the POK and PSK samples. The results show that PSK has important applications in subgrade or building grouting materials and in cement-soil mixing piles (walls).
\end{abstract}

Keywords: slag Portland cement; carbonation durability; carbonation depth; uniaxial compressive strength test (UCST)

\section{Introduction}

Coastal beach and soft foundation reinforcement is a common engineering problem. Cement soil reinforcement is one of the most commonly used, convenient, and economical methods. However, the manufacture of traditional cement consumes large amounts of energy. With the global promotion of green, carbon neutral development, new requirements are being adopted to reduce cement energy consumption [1]. Slag Portland cement has a beneficial environmental effect because its raw material is an industrial by-product (blast furnace slag). The research on ordinary Portland cement-reinforced soil has progressed significantly, and ordinary Portland cement is widely used as a soil-reinforcement agent. 
Kang et al. [2,3] studied the change of unconfined compressive strength of ordinary Portland cement-reinforced soil under different curing times, and measured the effect of curing time on its strength. Pu et al. [4] studied the mechanical properties and micro-properties of ordinary Portland cement-solidified soil. Their tests showed that the unconfined compressive strength of cement-reinforced soil increases with an increase in cement content. Kim et al. [5] obtained the dynamic and static characteristics of ordinary Portland cementreinforced soil through unconfined compression testing; they demonstrated that the unconfined compressive strength of ordinary Portland cement-reinforced soil increases with time. Yao et al. [6] studied the effect of curing time of ordinary Portland cement-reinforced soil on unconfined compressive strength, and concluded that the strength increased with increased curing time. Ding et al. [7] studied the effect of consolidation time on the unconfined compressive strength of soil strengthened with ordinary Portland cement. Zhou et al. [8] carbonized ordinary Portland cement-reinforced soil. The results show that carbonation reduces the strength of ordinary Portland cement-reinforced soil. Shah et al. [9] showed that the volume of all cement shrinks after carbonation. Liu et al. [10] observed through $\mathrm{X}$-ray diffraction (XRD) tests that the main polycrystalline form of carbonated ordinary Portland cement is calcite $\left(\mathrm{CaCO}_{3}\right)$.

In addition to the voluminous research on ordinary Portland cement, the research on slag Portland cement is becoming more and more mature. Luo et al. [11] studied the influence of curing temperature on the compaction carbonation behavior of steel slag. Sanjuán et al. [12] observed the high carbonation rate of abrasive slag cement, and proposed a calculation model of carbonation depth and $\mathrm{CO}_{2}$ diffusion coefficient in ground granulated blast-furnace slag mortars as a function of the curing period and the amount of ground granulated blast-furnace slag. Sanjuán et al. [13] studied the carbonation mechanism of calcium hydroxide $(\mathrm{CH})$ and hydrogenated calcium silicate $(\mathrm{C}-\mathrm{S}-\mathrm{H})$ from the aspects of microstructure and moisture characteristics. Andrade and Sanjuán [14] studied the hydration and fixation of carbon dioxide through a large number of experiments and described the factors that affect the efficiency of carbon dioxide fixation. Sanjuán [15] studied the effect of carbon dioxide absorption by blast-furnace-slag mortar on curing strength. Sanjuán et al. [16] also analyzed the advantages and disadvantages of the ground granulated blast-furnace slag efficiency coefficient and gave their own empirical choices. $\mathrm{Pu}$ et al. [17] studied the carbonation resistance of slag concrete and found that the strength of slag concrete did not decrease significantly after complete carbonation. Wu et al. [18] employed XRD and scanning electron microscopy (SEM) to examine the micro-morphology of solidified soil and obtain the mineralogical differences with erosion time. Monsif et al. [19] found that the strength of slag Portland cement-reinforced soil increased with time. Allahverdi et al. [20] studied the chemical activity of slag after adding ordinary Portland cement to it. The results showed that the chemical activity was significantly improved by adding slag to cement. Ge et al. [21] studied the effect of slag Portland cement on soil strength and concluded that the unconfined compressive strength increased with the increase of the ratio of slag cement to soil. Liu et al. [22] studied the strength characteristics of slag Portland cement-reinforced soil under different curing times; their research showed that slag Portland cement-reinforced soil can effectively improve soil strength. Saafan et al. [23] studied the microstructure, physicochemical properties, mechanical properties, and durability of slag Portland cement mortar.

Although many scholars have performed significant research on slag Portland cementreinforced soil, prior research on cement-reinforced soil has focused primarily on the strength and carbonation of ordinary Portland cement-reinforced soil, whereas the research on slag Portland cement has mainly focused on the mechanical and carbonation properties of pure mortar samples or concrete. The research on slag Portland cement-reinforced soil is relatively sparse, focusing mainly on its mechanical properties, and there has been little research on the carbonation properties of slag Portland cement-reinforced soil. Carbonation performance is an important index of cement-reinforced soil. In order to understand 
whether slag Portland cement can replace ordinary Portland cement for soil reinforcement, it is necessary to study its carbonation performance.

In this work, the carbonation durability of slag Portland cement-reinforced soil and that of ordinary Portland cement-reinforced soil were studied, analyzed, and compared through a combination of macro tests and micro tests. In the macro test, the carbonation behaviors of slag Portland cement-reinforced soil and ordinary Portland cement-reinforced soil were studied through carbonation depth testing and unconfined compression testing. Through XRD and SEM tests, the microstructure characteristics, pore distribution, degree of particle cementation, and hydration product morphology of reinforced soil samples were analyzed; and subsequently the hydration mechanisms and micro characteristics of hydration reaction products of reinforced soil before and after carbonation were analyzed. Combining the results obtained from the macro tests and the micro tests, it can be concluded that slag Portland cement-reinforced soil is easier to carbonize than ordinary Portland cement-reinforced soil, and that carbonation increases the strength of the cement-soil. Therefore, slag Portland cement can be used for the reinforcement and improvement of soil having poor engineering characteristics.

\section{Materials and Methods}

\subsection{Experimental Materials and Sample Preparation}

In order to test the reinforcement effect of slag cement on soil, ordinary Portland cement was designated as the control substance. The main experimental materials were kaolin, P.O 42.5 ordinary Portland cement and P.S.A 42.5 slag Portland cement. The kaolin was produced by Shanghai Jiujie Industrial Co., Ltd (Shanghai, China).; the P.O 42.5 ordinary Portland cement was produced by Shandong Weizhou Cement Technology Co., Ltd. (Weifang, China); and the P.S.A 42.5 slag Portland cement was produced by Sinoma Zhuzhou Cement Co., Ltd (Zhuzhou, China). Table 1 [24] shows the specific parameters.

Table 1. Basic chemical properties of the experimental materials.

\begin{tabular}{|c|c|c|c|c|c|c|c|c|c|c|c|}
\hline $\begin{array}{c}\text { Material } \\
\text { Type }\end{array}$ & $\begin{array}{c}\mathrm{CaO} \\
(\%)\end{array}$ & $\begin{array}{c}\mathrm{SiO}_{2} \\
(\%)\end{array}$ & $\begin{array}{c}\mathrm{Al}_{2} \mathrm{O}_{3} \\
(\%)\end{array}$ & $\begin{array}{l}\mathrm{SO}_{3} \\
(\%)\end{array}$ & $\begin{array}{c}\mathrm{Fe}_{2} \mathrm{O}_{3} \\
(\%)\end{array}$ & $\begin{array}{c}\mathrm{MgO} \\
(\%)\end{array}$ & $\begin{array}{c}\mathrm{NaO}_{2} \\
(\%)\end{array}$ & $\begin{array}{c}\mathrm{K}_{2} \mathrm{O} \\
(\%)\end{array}$ & $\begin{array}{c}\mathrm{Cl} \\
(\%)\end{array}$ & $\begin{array}{l}\text { LOI } \\
(\%)\end{array}$ & $\begin{array}{c}\text { Specific } \\
\text { Surface Area } \\
\left(\mathrm{m}^{2} / \mathrm{kg}\right)\end{array}$ \\
\hline Kaolin & 0.55 & 57.03 & 30.32 & 0.07 & 1.42 & 0.49 & / & / & / & / & / \\
\hline P.S.A 42.5 & 51.81 & 26.48 & 10.09 & 2.54 & 2.58 & 3.96 & / & / & / & 1.33 & 326 \\
\hline P.O 42.5 & 56.23 & 25.09 & 6.02 & 2.13 & 3.87 & 2.38 & 0.46 & 0.59 & 0.05 & 2.55 & 341 \\
\hline
\end{tabular}

The test materials were analyzed by XRD. According to the XRD pattern, the main composition of kaolin is $\mathrm{Al}\left[\mathrm{Si}_{4} \mathrm{O}_{10}\right](\mathrm{OH})_{8}$. The main components of P.O 42.5 and P.S.A 42.5 are $\mathrm{C} 3 \mathrm{~S}, \mathrm{SiO}_{2}, \mathrm{CaSO}_{4}$. This corresponds to the main chemical composition of each test material in Table 1.

The P.O 42.5 or P.S.A 42.5 cement was mixed with kaolin at a mass ratio of 10:3 [25], and was used to fabricate two types of samples: Sample 1 was a $100 \mathrm{~mm}$ cube, and Sample 2 was a cylindrical test block with a radius of $50 \mathrm{~mm}$ and a height of $100 \mathrm{~mm}$. Samples 1 and 2 were fabricated from each of two different sample materials: P.O $42.5+$ kaolin (POK) and P.S.A $42.5+$ kaolin (PSK). Depending on the desired curing time and processing sequence, the prepared samples needed standard curing first, and some needed an additional carbonation curing step. The standard curing temperature was $20{ }^{\circ} \mathrm{C}$ at a relative humidity of $95 \%$; the carbonation curing temperature was $20{ }^{\circ} \mathrm{C}$ at a relative humidity of $70 \%$; and the $\mathrm{CO}_{2}$ concentration was maintained at $20 \%[26,27]$. Sample preparation is shown in Table 2. 
Table 2. Sample preparation and test type.

\begin{tabular}{|c|c|c|c|c|c|c|c|c|}
\hline \multirow{3}{*}{$\begin{array}{l}\text { Sample } \\
\text { Type }\end{array}$} & \multirow{3}{*}{ Sample Material } & \multicolumn{4}{|c|}{ Curing Sequence (Time and Sequence) } & \multicolumn{3}{|c|}{ Test Sequence } \\
\hline & & \multicolumn{2}{|c|}{ a. Standard Curing } & \multicolumn{2}{|c|}{ b. Carbonation Curing } & \multirow{2}{*}{$\begin{array}{l}\text { a. Phase I Test } \\
\text { Test Type }\end{array}$} & \multirow{2}{*}{\multicolumn{2}{|c|}{$\begin{array}{l}\text { b. Phase II Test } \\
\text { Test Type }\end{array}$}} \\
\hline & & Time & Quantity & Time & Quantity & & & \\
\hline \multirow{8}{*}{ Sample 1} & \multirow{3}{*}{$\begin{array}{c}\text { P.O } 42.5+\text { Kaolin } \\
(\text { POK })\end{array}$} & \multirow{3}{*}{28} & \multirow{3}{*}{12} & 3 & 3 & \multirow{8}{*}{ CDT } & & \\
\hline & & & & 7 & 3 & & & \\
\hline & & & & 14 & 3 & & & \\
\hline & \multirow{5}{*}{$\begin{array}{c}\text { P.S.A } 42.5+\text { Kaolin } \\
\text { (PSK) }\end{array}$} & \multirow{5}{*}{28} & & 28 & 3 & & & \\
\hline & & & \multirow{4}{*}{12} & 3 & 3 & & & I \\
\hline & & & & 7 & 3 & & & \\
\hline & & & & 14 & 3 & & & \\
\hline & & & & 28 & 3 & & & \\
\hline \multirow{4}{*}{ Sample 2} & P.O 42.5 + Kaolin & 56 & 3 & / & / & \multirow{4}{*}{ CUST } & XRD & SEM \\
\hline & $(\mathrm{POK})$ & 28 & 3 & 28 & 3 & & $\mathrm{XRD}$ & SEM \\
\hline & P.S.A $42.5+$ Kaolin & 56 & 3 & / & / & & XRD & SEM \\
\hline & $(\mathrm{PSK})$ & 28 & 3 & 28 & 3 & & $\mathrm{XRD}$ & SEM \\
\hline
\end{tabular}

Remarks: CDT is the carbonation depth test. CUST is the uniaxial compressive strength test.

\subsection{Experimental Scheme}

The tests were carried out after the sample had been cured for the specified time. The phase I tests were performed first: a carbonation test for sample 1 and a uniaxial compressive strength test for sample 2. During the phase II test, a middle fragment of sample 2 that had been damaged by the compressive testing was used for the XRD and SEM tests.

\subsubsection{Carbonation Test (CDT)}

After 28 days of standard curing of sample 1, carbonation curing was carried out. The samples cured for 3, 7, 14, and 28 days, were used for the carbonation test. The test block was cut along the center line of the upper surface, and 1\% phenolphthalein ethanol solution was sprayed on the section; in this test, the non-carbonized area shows red, the carbonized area does not change color, and the height of the red area is the carbonation depth. At least 5 measuring points were taken for each test piece, and the average depth of the measuring points was defined as the carbonation depth. Three samples were used for each curing time, and the average carbonation depth of the three samples was taken as the carbonation depth at that curing time.

\subsubsection{Uniaxial Compressive Strength Test (CUST)}

The uniaxial compressive strength test was performed after sample 2 reached its curing time. The uniaxial compressive strength test was divided into four test groups: (1) a POK sample that had been cured for 56 days (standard curing for 56 days, abbreviated as S56); (2) a POK sample that had been carbonized for 28 days after standard curing (carbonation curing for 28 days, abbreviated as C28); (3) a PSK sample that had received standard curing for 56 days (S56); (4) a PSK sample that had received standard curing for 28 days and was then carbonized for 28 days (S28 + C28). A microcomputer controlled electro-hydraulic servo universal testing machine was used to test the samples. The loading rate was $0.5 \mathrm{MPa} / \mathrm{s}$, and the average value of three samples in each group was taken as the uniaxial compressive strength of this group.

\subsubsection{XRD and SEM + EDS Tests}

The samples used in the XRD and SEM + EDS tests were the fragments of sample 2 after its failure during the uniaxial compressive strength test, which were then ground into powder to be used as test samples for the current test. A DX-2700 X-ray diffractometer was used for the XRD, and a Quanta250 scanning electron microscope was used for the SEM + EDS tests. These two pieces of equipment, shown in Figure 1, are located at the National Engineering Laboratory of Shandong University of science and technology. 


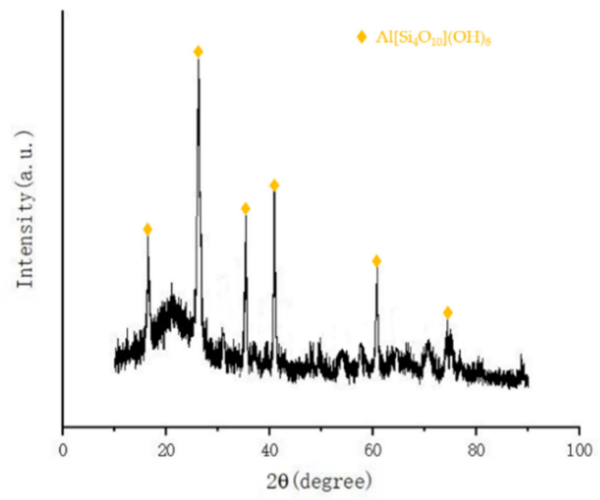

(a) XRD of kaolin

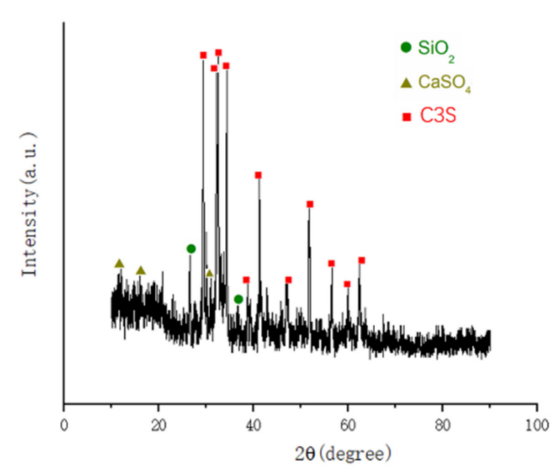

(b) XRD of P.O 42.5

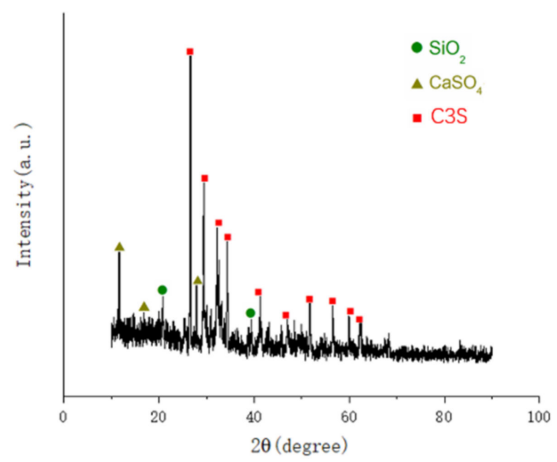

(c) XRD of P.S.A 42.5

Figure 1. XRD of raw materials.

\section{Results}

In accordance with the experimental group design in Table 2, the carbonation test, uniaxial ground pressure strength test, SEM + EDS test, and XRD test were carried out for POK and PSK sample materials; and the collected test data were processed and analyzed. The specific test results will be described in detail in the following subsections.

\subsection{Analysis of Carbonation Depth Test (CDT) Results}

The carbonation depths of POK and PSK samples after 3, 7, 14, and 28 days of carbonation curing were tested using a phenolphthalein reagent. The test results are shown in Figures 2 and 3. The phenolphthalein reagent used was a weak acidic solution that is colorless in acidic solutions and turns red in alkaline solutions. The greater the $\mathrm{OH}^{-}$ concentration of the solution, the darker the color of the reagent. It can be seen from these two groups of pictures that for the same group of samples, the carbonation depth also deepens with increasing curing time. This is because a large amount of $\mathrm{OH}^{-}$is produced in the hydration process of cement, and the sample is alkaline at the initial stage of preparation. However, $\mathrm{CO}_{2}$ in the carbonation curing environment continuously penetrates into the sample from outside and reacts with $\mathrm{OH}^{-}$in the carbonation process, which greatly reduces the content of $\mathrm{OH}^{-}$; therefore, the carbonation depth increases with age. At the same time, the red color of the phenolphthalein reagent on POK is significantly deeper than that on PSK, and the red color of PSK becomes lighter and lighter with the increase of age. According to the published literature [28,29], slag cement contains a number of active substances such as $\mathrm{SiO}_{2}, \mathrm{Al}_{2} \mathrm{O}_{3}$, and $\mathrm{Fe}_{2} \mathrm{O}_{3}$ that can also react with $\mathrm{OH}^{-}$and reduce the content of $\mathrm{OH}^{-}$in the sample even further, resulting in the light color seen in the phenolphthalein tests of PSK. 


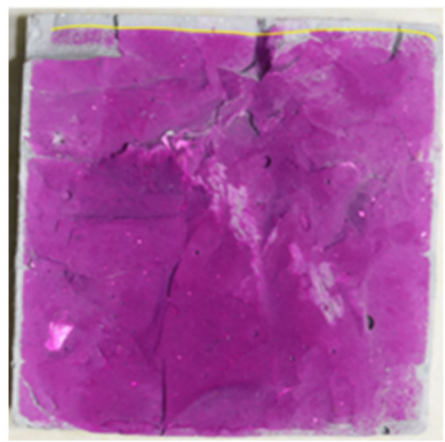

(a)

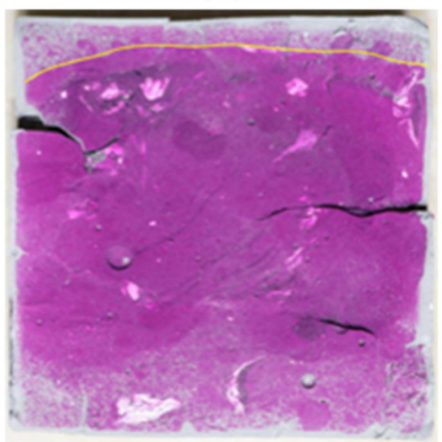

(c)

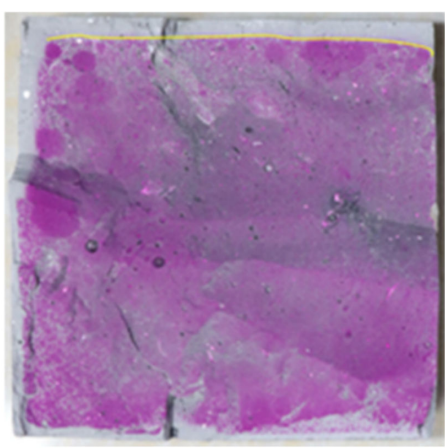

(b)

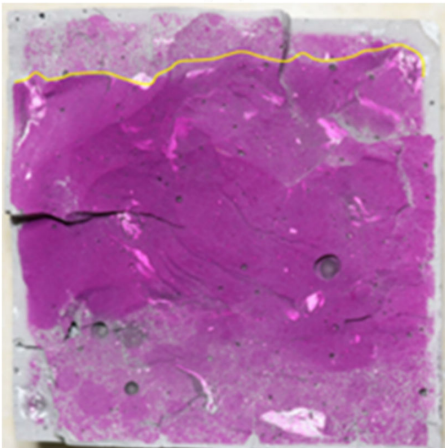

(d)

Figure 2. Phenolphthalein test diagram of carbonation depth in POK samples that had been subjected to differing amounts of carbonation curing-(a) $3 \mathrm{~d}$ (b) $7 \mathrm{~d}$ (c) $14 \mathrm{~d}$ and (d) $28 \mathrm{~d}$.

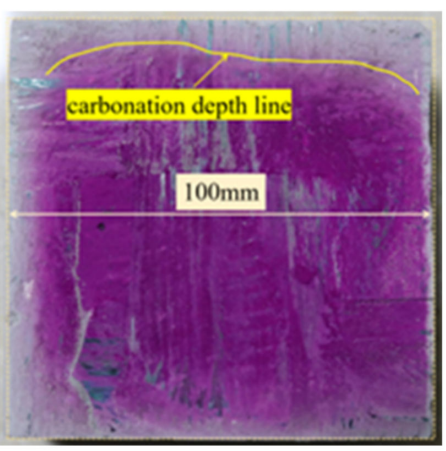

(a)

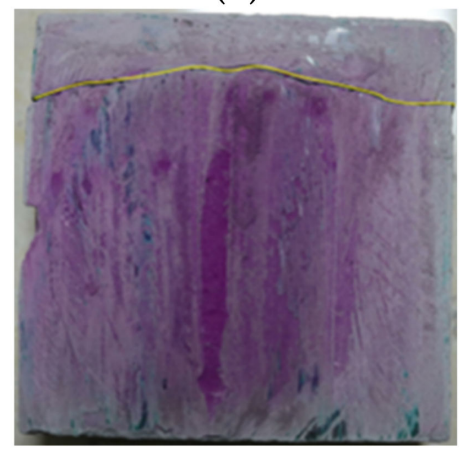

(c)

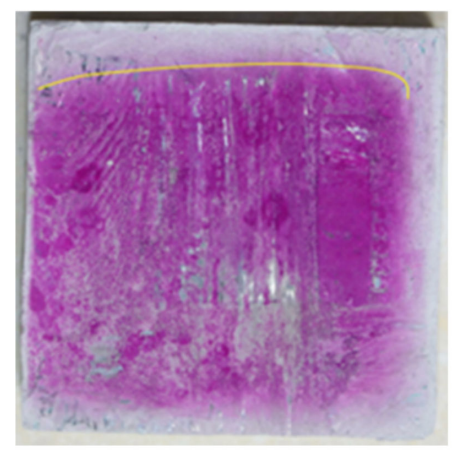

(b)

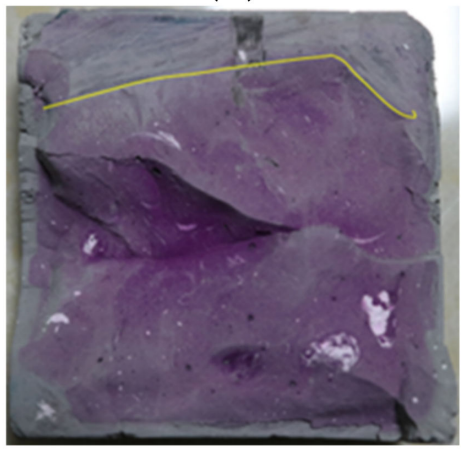

(d)

Figure 3. Phenolphthalein test diagram of carbonation depth in PSK samples that had been subjected to differing amounts of carbonation curing-(a) $3 \mathrm{~d}$ (b) $7 \mathrm{~d}$ (c) $14 \mathrm{~d}$ and (d) $28 \mathrm{~d}$. 
As can be seen from Figure 4, the carbonation depth of POK increases from the initial $3.7 \mathrm{~mm}(0 \mathrm{~d})$ to $22.6 \mathrm{~mm}(28 \mathrm{~d})$, and the carbonation depth of PSK increases from the initial $8.7 \mathrm{~mm}(0 \mathrm{~d})$ to $30.1 \mathrm{~mm}(28 \mathrm{~d})$. The carbonation depth of both materials increased with increasing curing time, but the rate of increase gradually slowed down for both the materials. Moreover, the carbonation depth of PSK is significantly higher than that of POK at any given time. The reason for this phenomenon is similar to the principle of color depth of phenolphthalein. It is because $\mathrm{CO}_{2}$ and the active substances in slag cement react with $\mathrm{OH}^{-}$, which increases the carbonation effect of PSK and makes its carbonation depth significantly higher than that of POK. Therefore, the carbonation durability of slag cementreinforced soil is significantly weaker than that of ordinary Portland cement. Shi et al. [30], Bakharev et al. [31], Puertas et al. [32], and Pacheco-Torgal [33] also found that slag cement is more prone to carbonation.

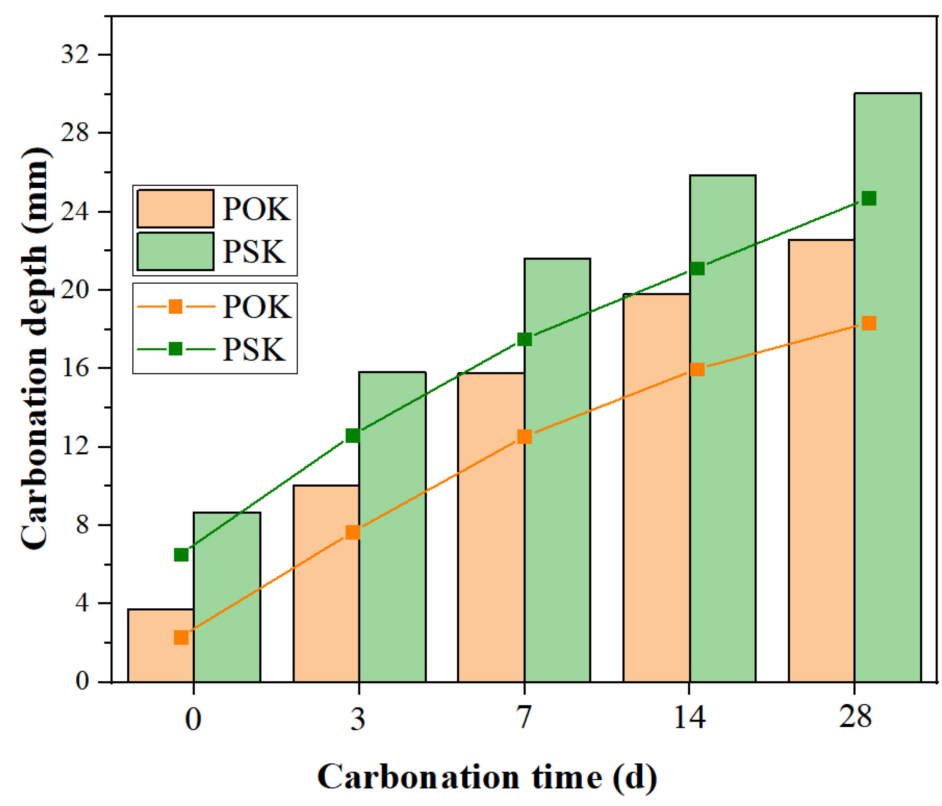

Figure 4. Relationship between carbonation depth and curing time of sample.

\subsection{Analysis of CUST Results}

Observe Figure 5, the uniaxial compressive strength of the same sample is different under different curing conditions. Specifically, put POK under the standard curing for 28 days and under the carbonation curing for 28 days (S28 + C28), its uniaxial compressive strength is $17.6 \mathrm{MPa}$. Then, put POK under the standard curing for 56 days(S56), its uniaxial compressive strength is $15.12 \mathrm{MPa}$. The uniaxial compressive strength of POK under carbonation curing (S28 + C28) is $16.4 \%$ higher than the uniaxial compressive strength of POK without carbonation curing condition. Similarly, put PSK under the standard curing for 28 days and under the carbonation curing for 28 days (S28 + C28), its uniaxial compressive strength is $24.27 \mathrm{MPa}$. Then, put PSK under the standard curing for 56 days (S56), its uniaxial compressive strength is $20.3 \mathrm{MPa}$. The uniaxial compressive strength of PSK under carbonation curing (S28 + C28) is 19.56\% higher than the uniaxial compressive strength of PSK without carbonation curing condition. In general, the uniaxial compressive strength of the sample was improved by the curing method of standard curing for 28 days and carbonation curing for 28 days (S28 + C28). In other words, carbonation curing enhances uniaxial compressive strength. Therefore, carbonation is beneficial to improve the strength of concretes $[34,35]$. 


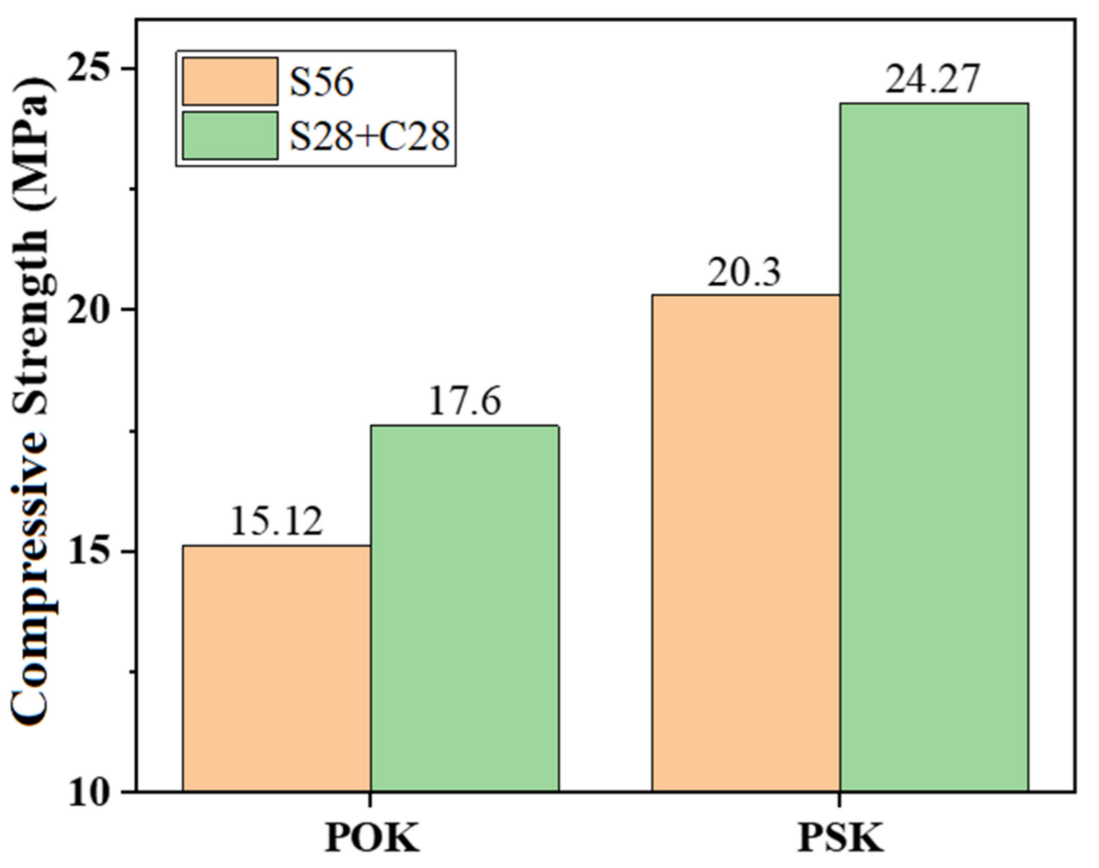

Sample material

Figure 5. Uniaxial compressive strength of POK and PSK samples after S56 and S28 + C28 aging.

It can also be observed in Figure 5 that the uniaxial compressive strength of different samples is different even though samples are under the same curing conditions. Specifically, put PSK and POK under the standard curing for 56 days (S56), the uniaxial compressive strength of PSK is $20.3 \mathrm{MPa}$, but the uniaxial compressive strength of POK is $15.12 \mathrm{MPa}$. The strength of PSK is 34.26\% higher than the strength of POK. In the same way, put PSK and POK under the standard curing for 28 days and under the carbonation curing for 28 days (S28 + C28), the uniaxial compressive strength of PSK is $24.27 \mathrm{MPa}$, but the uniaxial compressive strength of POK is $17.6 \mathrm{MPa}$. The strength of PSK is $37.9 \%$ higher than the strength of POK. In general, the uniaxial compressive strength of PSK is obviously greater than POK, when they are under different curing conditions. Susan A. Bernal [36] also reached a similar conclusion.

There are two reasons for the phenomenon: (1) $\mathrm{CH}$ produced in the hydration reaction is harmful to strength. In the carbonation curing process, due to the high concentration of $\mathrm{CO}_{2}$ in the environment, carbonation is more sufficient, then the content of $\mathrm{CH}$ was decreased greatly, and the main precipitate that is $\mathrm{CaCO}_{3}$ increased [37]. (2) Active substances such as $\mathrm{SiO}_{2}, \mathrm{Al}_{2} \mathrm{O}_{3}$ and $\mathrm{Fe}_{2} \mathrm{O}_{3}$ contained in slag cement react with $\mathrm{CO}_{2}$ in carbonation curing environment to form $\mathrm{CaSiO}_{3}, \mathrm{CaO} \cdot \mathrm{Al}_{2} \mathrm{O}_{3} \cdot 6 \mathrm{H}_{2} \mathrm{O}$ and other substances. Both reactions consume $\mathrm{OH}^{-}$produced in the process of cement hydration, which is unfavorable for reinforced concrete and may lead to reinforcement corrosion. However, for the reinforced soil structure without steel reinforcement, the generated solid matter increases the strength of the sample. Therefore, after carbonation curing, the strength of the cement reinforced soil sample is improved.

\subsection{Analysis of SEM and EDS Data}

Through the SEM + EDS method, combined with the cement hydration and carbonation results, as well as using XRD technology, we can roughly judge the products created during cement hydration and carbonation, and determine the main products.

Different substances formed by cement hydration and carbonation have their unique shapes under SEM observation. It can be seen from Figure $6 a-d$ that after carbonation of the POK and PSK samples, the amount of calcium carbonate $\left(\mathrm{CaCO}_{3}\right)$ increases significantly, 
mainly in the form of sheet overlap, particle agglomeration, and blocks. Ettringite or alumina/ferric oxide/trisulfate (AFt) is needle-shaped or rod-shaped and becomes thicker after carbonation. Before and after carbonation, hydrogenated calcium silicate (C-S-H) is abundant, mainly in cloud clusters and clusters. The amount of $\mathrm{CH}$ (mainly present as hexagonal flakes) decreases significantly [38]. At the same time, the sample structure is more compact after carbonation, which mainly leads to the increase in sample strength. By comparing the POK sample in Figure $6 \mathrm{~b}$ with the PSK sample in Figure $6 \mathrm{~d}$, it can be seen that after 28 days of carbonation, the $\mathrm{CaCO}_{3}$ blocks in the POK sample are dense, and the needle shape of AFt in the PSK sample is significantly increased and coarsened, which is due to the partial formation of $\mathrm{C}-\mathrm{S}-\mathrm{H}, \mathrm{AFt}$, etc., by the active substances in the PSK sample under the action of the hydration reactions [39]. The average content of C-S-H is high, but the boundary of the C-S-H cloud cluster in the PSK sample is clearer and is arranged more densely [27]. After carbonation of POK and PSK, CH was mostly consumed and therefore, decreased significantly.

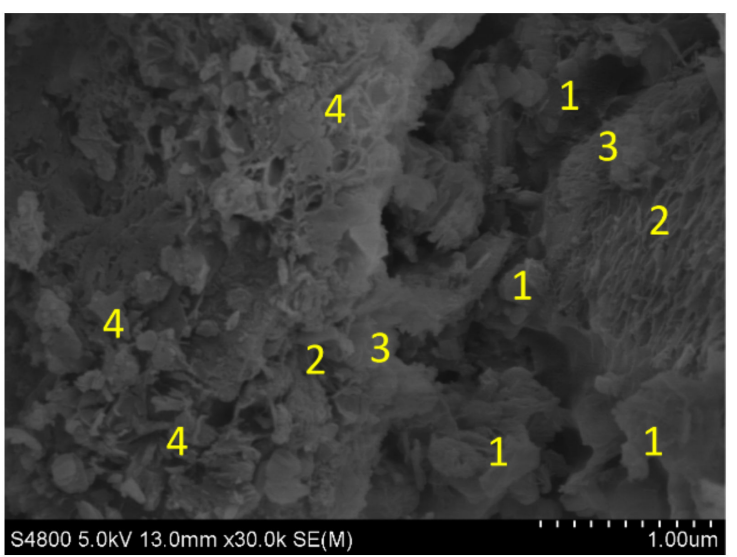

(a) SEM photographs of POK sample cured for S56

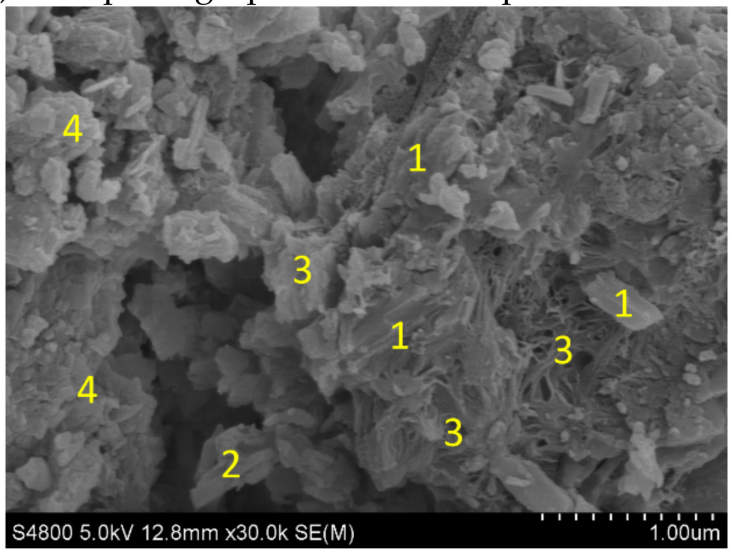

(c) SEM photographs of PSK sample cured for S56

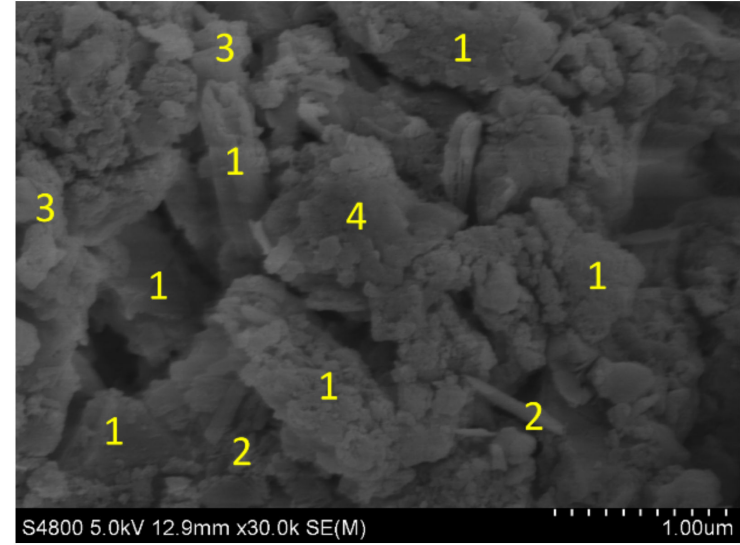

(b) SEM photographs of POK sample cured for S28 + C28

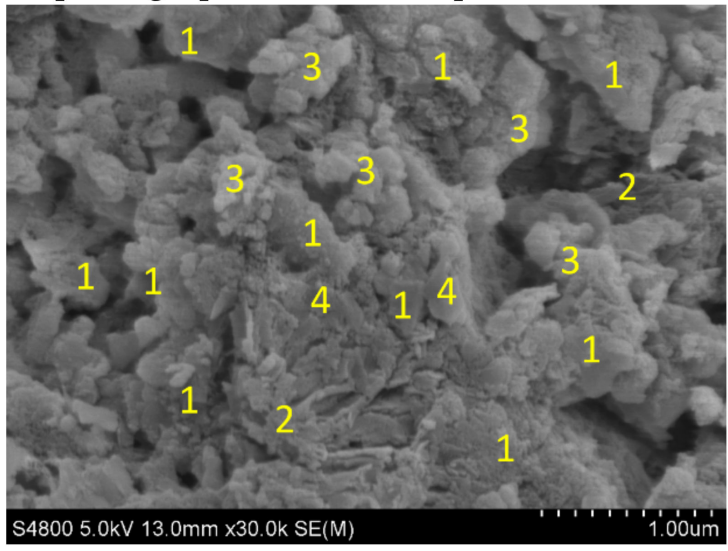

(d) SEM photographs of PSK sample cured for S28 + C28

Figure 6. SEM photographs of samples. The numbers in the figures denote: 1 . Calcium carbonate $\left(\mathrm{CaCO}_{3}\right)$. 2. Ettringite (AFt). 3. Hydrogenated calcium silicate (C-S-H). 4. Calcium hydroxide (CH).

The hydration process of cement produces a large amount of $\mathrm{CH}$, but the carbonation process consumes $\mathrm{CH}$, and the active substances in PSK also react with $\mathrm{CH}$, increasing the contents of $\mathrm{CaCO}_{3}, \mathrm{C}-\mathrm{S}-\mathrm{H}$ and AFt. Thus, the strength of the sample is improved. The large consumption of $\mathrm{CH}$ leads to a reduction in the alkalinity of the sample, which is confirmed by the light discoloration of the PSK sample in Section 3.1 and the strength analysis results in Section 3.2.

The EDS spectra were measured using SEM. It can be seen from Figure 7 that the main elements in all the samples are $\mathrm{O}, \mathrm{C}, \mathrm{Ca}, \mathrm{Si}$, and $\mathrm{Al}$; and the samples also contain small 
amounts of $\mathrm{Mg}, \mathrm{Na}, \mathrm{S}$, and Fe. It can be seen by comparing Figure $7 \mathrm{a}-\mathrm{d}$ that the mass ratio of $\mathrm{C}$ to $\mathrm{O}$ increases significantly after carbonation in both the POK sample and the PSK sample. This is caused by the sample absorbing $\mathrm{CO}_{2}$ in the carbonation environment. It can be seen from Figure 7b,d that after carbonation of the PSK sample, the content of C and $\mathrm{O}$ increases compared with standard curing conditions, but the increase is less than that of the POK sample in the carbonation environment. This is because the active substances in the PSK sample react with $\mathrm{CH}$ while carbonizing. To some extent, this reduces the ability of the PSK to be carbonized by $\mathrm{CO}_{2}$ and therefore, the amount absorbed is relatively less.

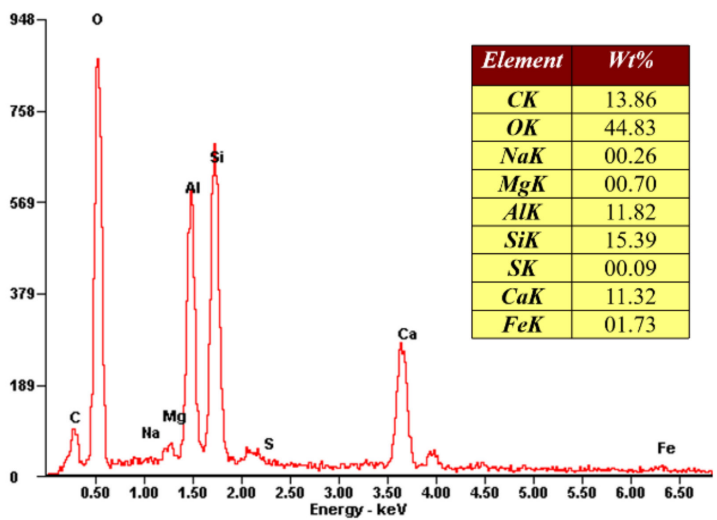

(a) EDS patterns of POK sample cured for S56

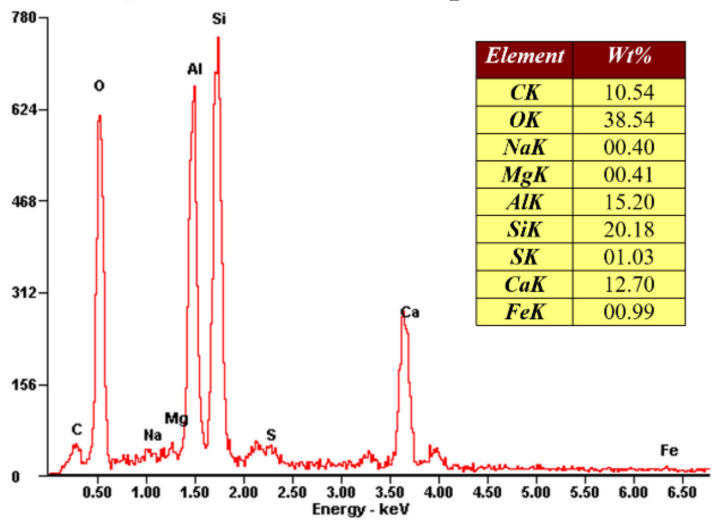

(c) EDS patterns of PSK sample cured for S56

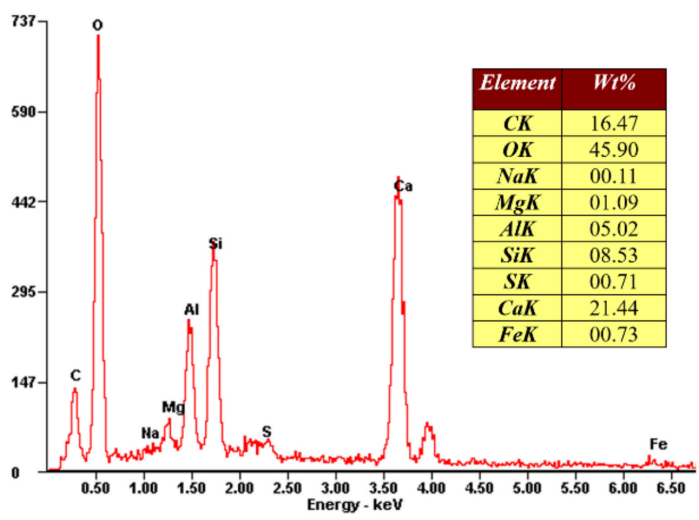

(b) EDS patterns of POK sample cured for S28 + C28

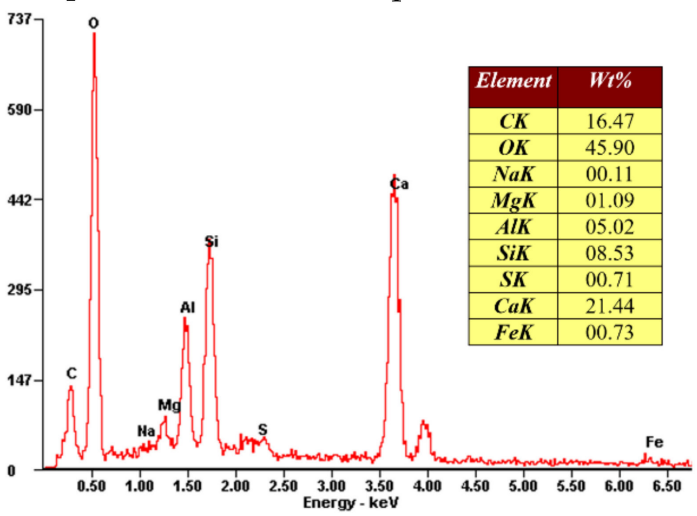

(d) EDS patterns of PSK sample cured for S28 + C28

Figure 7. EDS patterns of various samples.

\subsection{Analysis of XRD Test Results}

It can be seen from Figure 8 that the products of POK and PSK samples in the standard curing and carbonation environments are the same, and the main products after hydration and carbonation are $\mathrm{CaCO}_{3}, \mathrm{CaSO}_{4}, \mathrm{SiO}_{2}$ and Aft. By combining SEM + EDS analysis and hydration-carbonation reaction analysis, there are other products such as $\mathrm{CH}, \mathrm{C}-\mathrm{S}-\mathrm{H}, \mathrm{AFm}$, $\mathrm{C} 2 \mathrm{~S}, \mathrm{C}_{3} \mathrm{AH}_{6}$, etc. [40-42]. 


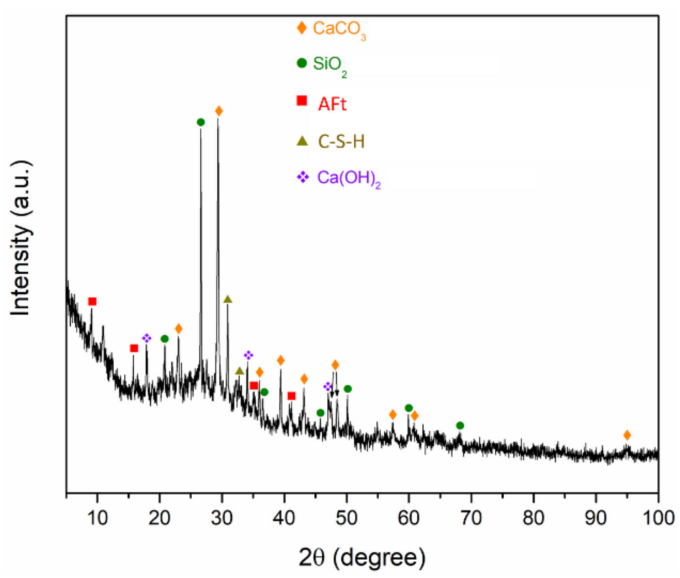

(a) XRD patterns of POK sample cured for S56

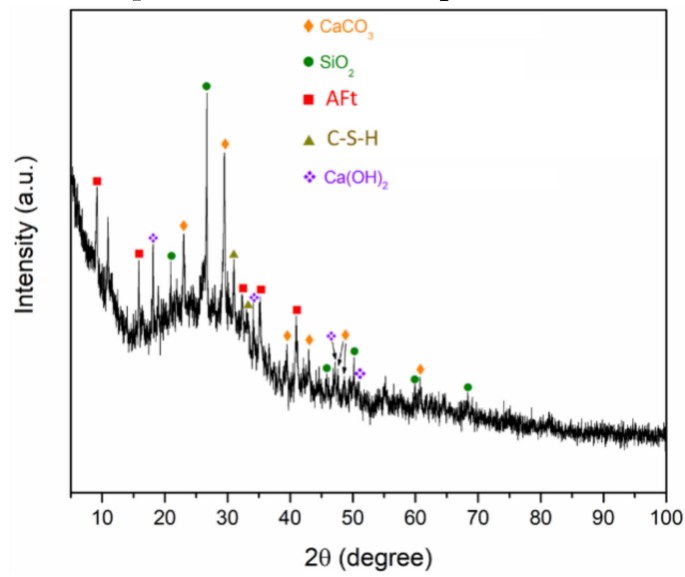

(c) XRD patterns of PSK sample cured for S56

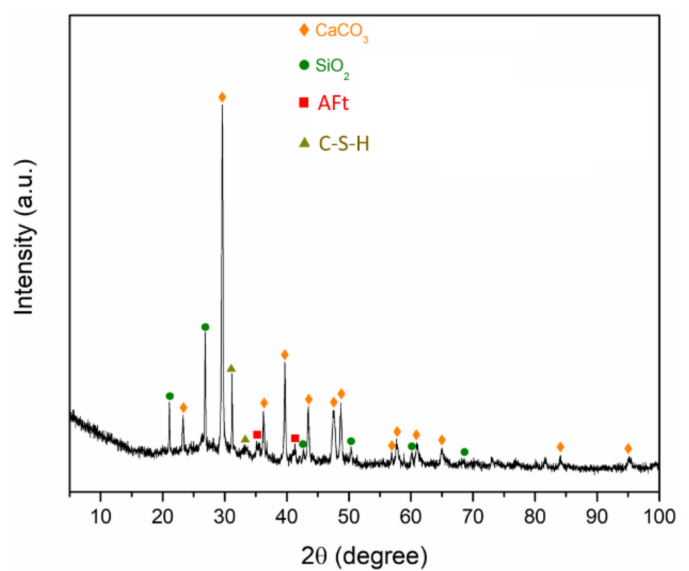

(b) XRD patterns of POK sample cured for S28 + C28

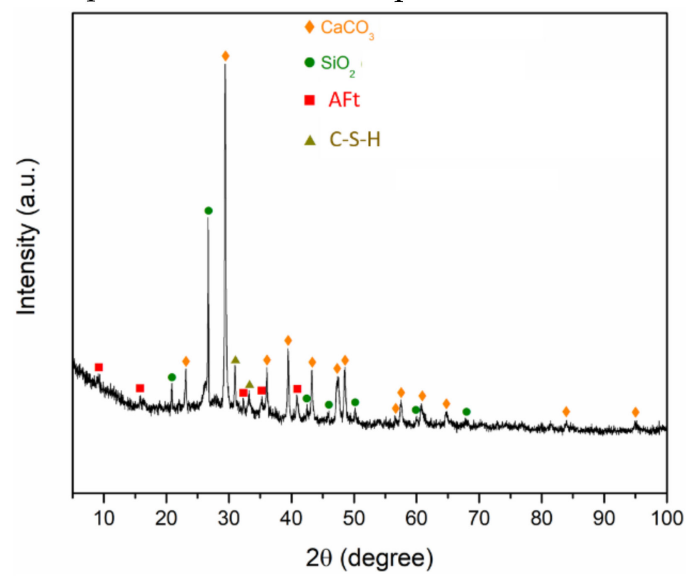

(d) XRD patterns of PSK sample cured for S28 + C28

Figure 8. XRD patterns of samples.

By comparing Figure $8 \mathrm{~b}$ with Figure $8 \mathrm{a}$, and Figure $8 \mathrm{~d}$ with Figure $8 \mathrm{c}$, it can be seen that after carbonation of the POK and PSK samples, the amount of $\mathrm{CaCO}_{3}$ increased significantly and that the increase was greater in the $\mathrm{POK}$. This is because the carbonation reaction is more sufficient. More $\mathrm{CH}$, Aft, $\mathrm{AFm}$ and $\mathrm{CO}_{2}$ produced $\mathrm{CaCO}_{3}$ and other products $[43,44]$. The reaction formulas are shown in Equations (1)-(3). The strength of the sample increases with the increase of $\mathrm{CaCO}_{3}$ content and the decrease of $\mathrm{CH}$ content, this is consistent with the conclusion in Section 3.2.

$$
\mathrm{Ca}(\mathrm{OH})_{2}+\mathrm{H}_{2} \mathrm{CO}_{3} \rightarrow \mathrm{CaCO}_{3}+2 \mathrm{H}_{2} \mathrm{O}
$$

$3 \mathrm{CaO} \cdot \mathrm{Al}_{2} \mathrm{O}_{3} \cdot 3 \mathrm{CaSO}_{4} \cdot 32 \mathrm{H}_{2} \mathrm{O}+3 \mathrm{CO}_{2} \rightarrow 3 \mathrm{CaCO}_{3}+3 \mathrm{CaSO}_{4}+\mathrm{Al}_{2} \mathrm{O}_{3} \cdot \mathrm{xH}_{2} \mathrm{O}+(32-\mathrm{x}) \mathrm{H}_{2} \mathrm{O}$

$3\left(3 \mathrm{CaO} \cdot \mathrm{Al}_{2} \mathrm{O}_{3} \cdot \mathrm{CaSO}_{4} \cdot 12 \mathrm{H}_{2} \mathrm{O}\right)+9 \mathrm{CO}_{2} \rightarrow 9 \mathrm{CaCO}_{3}+3 \mathrm{CaSO}_{4}+3 \mathrm{Al}_{2} \mathrm{O}_{3} \cdot x \mathrm{H}_{2} \mathrm{O}+(32-3 \mathrm{x}) \mathrm{H}_{2} \mathrm{O}$

By comparing Figure $8 \mathrm{~b}$ with Figure $8 \mathrm{~d}$, it can be seen that after carbonation of the POK and PSK samples, the amount of $\mathrm{CaCO}_{3}$ in PSK is significantly higher than that in POK. This is because that $\mathrm{CH}$, one of the hydration products in PSK sample, reacts with active substance in PSK sample to produce C-S-H, etc. [45,46]. Thus, the strength of the sample increased. This is consistent with the conclusion in Section 3.2. At the same time, the active substances contained in the PSK samples react preferentially with $\mathrm{CH}$, thus competing for $\mathrm{CH}$ that should have been carbonized by $\mathrm{CO}_{2}$. Therefore, the $\mathrm{CO}_{2}$ absorbed by the PSK sample is less than that of the POK sample, and the content of $\mathrm{CaCO}_{3}$ in the POK sample is relatively high. This is consistent with the $\mathrm{CO}_{2}$ content described in Section 3.3. 


\section{Discussion and Suggestions}

The results of this study show that slag Portland cement is not suitable for reinforced concrete because of its high carbonation characteristics that can easily lead to reinforcement corrosion. However, its strength effectively improves after carbonation. Therefore, it can be widely used in foundation reinforcement, such as for the prevention of uneven settlement of subgrade or buildings, or as grouting material. Moreover, it can also be used in the construction of cement-soil mixing piles and walls.

\section{Conclusions}

By testing POK and PSK samples after curing in the S56 and S28 + C28 environments, the carbonation depth and sample strength were studied. The micro-morphology and elemental composition were tested by SEM + EDS, and the products of hydration and carbonation were analyzed by XRD. The specific conclusions are as follows:

(1) The content of $\mathrm{OH}^{-}$was reduced during hydration and carbonation of the PSK samples. The active substances contained in PSK samples can react with the $\mathrm{CH}$ produced during cement hydration to reduce the content of $\mathrm{OH}^{-}$. In the $\mathrm{S} 28+\mathrm{C} 28$ curing environment, $\mathrm{OH}^{-}$in the PSK samples reacts with $\mathrm{CO}_{2}$. Both processes greatly reduce the content of $\mathrm{OH}^{-}$.

(2) The POK and PSK samples were carbonized in the S28 + C28 environment. The carbonation depth in the PSK sample at each curing time was deeper than that of the POK sample, and the color of the phenolphthalein reagent on PSK was significantly lighter than in the case of the POK sample. This shows that the carbonation durability of slag Portland cement is weaker than that of ordinary Portland cement.

(3) The strength of the PSK sample after carbonation was higher than that without carbonation. The strength of the PSK sample after carbonation was higher than that of the POK sample after carbonation. This shows that the carbonation of slag Portland cement-reinforced soil improves its strength.

(4) After comprehensive analysis of SEM, EDS and XRD, the elements and products of POK and PSK samples before and after hydration and carbonation are basically the same. The main products after hydration and carbonation are $\mathrm{CaCO}_{3}, \mathrm{CaSO}_{4}$, $\mathrm{SiO}_{2}, \mathrm{Aft}, \mathrm{AFm}, \mathrm{CH}, \mathrm{C}-\mathrm{S}-\mathrm{H}, \mathrm{C} 2 \mathrm{~S}$, etc. The increase of crystals content such as calcium carbonate and the decrease of calcium hydroxide content are the main factors for the improvement of PSK sample strength.

Author Contributions: Conceptualization, F.W. and Q.W.; methodology, Y.M., H.Y. and Z.S.; formal analysis, Y.T. and D.W.; resources, Y.L.; data curation, Y.S.; writing-original draft preparation, R.Y.; investigation, H.S. (Hongxu Song) and H.S. (Haoran Sun); supervision, Z.H. All authors have read and agreed to the published version of the manuscript.

Funding: This research was funded by National Natural Science Foundation of China (NSFC) (No. 51778351) and SDUST Research Fund (No. 2018TDJH101).

Institutional Review Board Statement: This study has not been carried out on humans or animals. Informed Consent Statement: Not applicable.

Data Availability Statement: The data presented in this study are available on request from the corresponding author.

Conflicts of Interest: The authors declare no conflict of interest.

\section{References}

1. Sanjuán, M.Á.; Argiz, C.; Mora, P.; Zaragoza, A. Carbon dioxide uptake in the roadmap 2050 of the Spanish cement industry. Energies 2020, 13, 3452. [CrossRef]

2. Kang, G.; Tsuchida, T.; Kim, Y. Strength and stiffness of cement-treated marine dredged clay at various curing stages. Constr. Build. Mater. 2017, 132, 71-84. [CrossRef] 
3. Gyeong-o, K.; Takashi, T.; Athapaththu, A.M.R.G. Engineering behavior of cement-treated marine dredged clay during early and later stages of curing. Eng. Geol. 2016, 209, 163-174.

4. $\quad \mathrm{Pu}, \mathrm{S}$.; Zhu, Z.; Song, W.; Wan, Y.; Wang, H.; Song, S.; Zhang, J. Mechanical and microscopic properties of cement stabilized silt. KSCE J. Civ. Eng. 2020, 24, 2333-2344. [CrossRef]

5. Kim, A.R.; Chang, I.; Cho, G.C.; Shim, S.H. Strength and dynamic properties of cement-mixed korean marine clays. KSCE J. Civ. Eng. 2018, 22, 1150-1161. [CrossRef]

6. Yao, K.; Pan, Y.; Jia, L.; Yi, J.T.; Hu, J.; Wu, C. Strength evaluation of marine clay stabilized by cementitious binder. Mar. Georesources Geotechnol. 2020, 38, 730-743. [CrossRef]

7. Ding, Z.; Zhang, M.Y.; Li, S.L.; Wei, X.J.; Do, T.N. The pore pressure model of cement soil under cyclic loading. Mater. Res. Innov. 2015, 19 (Suppl. S8), 409-415. [CrossRef]

8. Zhou, Y.; Pan, L.; Tang, Q.; Zhang, Y.; Yang, N.; Lu, C. Evaluation of carbonation effects on cement-solidified contaminated soil used in road subgrade. Adv. Mater. Sci. Eng. 2018, 2018, 1-15. [CrossRef]

9. Shah, V.; Scrivener, K.; Bhattacharjee, B.; Bishnoi, S. Changes in microstructure characteristics of cement paste on carbonation. Cem. Concr. Res. 2018, 109, 184-197. [CrossRef]

10. Liu, W.; Lin, S.; Li, Y.; Long, W.; Dong, Z.; Tang, L. Slag blended cement paste carbonation under different $\mathrm{CO}_{2}$ concentrations: Controls on mineralogy and morphology of products. Materials 2020, 13, 3404. [CrossRef]

11. Luo, Z.T.; Wang, Y.; Yang, G.J.; Ye, J.Y.; Zhang, W.S.; Liu, Z.C.; Mu, Y.D. Effect of curing temperature on carbonation behavior of steel slag compacts. Constr. Build. Mater. 2021, 291, 123369. [CrossRef]

12. Sanjuán, M.Á.; Estévez, E.; Argiz, C.; Barrio, D.D. Effect of curing time on granulated blast-furnace slag cement mortars carbonation. Cem. Concr. Compos. 2018, 90, 257-265. [CrossRef]

13. Morandeau, A.; Thiéry, M.; Dangla, P. Investigation of the carbonation mechanism of $\mathrm{CH}$ and C-S-H in terms of kinetics, microstructure changes and moisture properties. Cem. Concr. Res. 2014, 56, 153-170. [CrossRef]

14. Andrade, C.; Sanjuán, M.Á. Updating carbon storage capacity of spanish cements. Sustainability 2018, 10, 4806. [CrossRef]

15. Sanjuán, M.Á.; Estévez, E.; Argiz, C. Carbon dioxide absorption by blast-furnace slag mortars in function of the curing intensity. Energies 2019, 12, 2346. [CrossRef]

16. Sanjuán, M.Á.; Piñeiro, A.; Rodríguez, O. Ground granulated blast furnace slag efficiency coefficient (k value) in concrete. Applications and limits. Mater. Construcción 2011, 61, 303-313. [CrossRef]

17. Pu, X.C.; Gan, C.C.; He, G.; Bai, G.; Wu, L.X.; Chen, M.Z. Study on durability of Alkali Slag concrete. Concrete 1991, 5, 13-20 + 46. (In Chinese)

18. Wu, Y.; Shi, K.; Yu, J.; Han, T.; Li, D. Research on strength degradation of soil solidified by steel slag powder and cement in seawater erosion. J. Mater. Civ. Eng. 2020, 32, 4020181. [CrossRef]

19. Monsif, M.Y.; Liu, J.; Gurpersaud, N. Microstructural analyses of cement-based binders in stabilizing Champlain Sea clay. Geotechnol. Geol. Eng. 2021, 39, 4963-4981. [CrossRef]

20. Allahverdi, A.; Maleki, A.; Mahinroosta, M. Chemical activation of slag-blended Portland cement. J. Build. Eng. 2018, 18, 76-83. [CrossRef]

21. Ge, L.; Wang, C.C.; Hung, C.W.; Liao, W.C.; Zhao, H. Assessment of strength development of slag cement stabilized kaolinite Constr. Build. Mater. 2018, 184, 492-501. [CrossRef]

22. Liu, L.; Zhou, A.; Deng, Y.; Cui, Y.; Yu, Z.; Yu, C. Strength performance of cement/slag-based stabilized soft clays. Constr. Build. Mater. 2019, 211, 909-918. [CrossRef]

23. Saafan, M.A.; Etman, Z.A.; Ellakany, D.M. Microstructure and durability of ground granulated blast furnace slag cement Mortars Iran. J. Sci. Technol. Trans. Civ. Eng. 2020, 45, 1457-1465. [CrossRef]

24. GB 175-2007; Common Portland Cement. State Administration for Market Regulation and Standardization Administration of the People's Republic of China: Beijing, China, 2007.

25. JGJ/T 233-2011; Specification for Mix Proportion Design of Cement Soil. Ministry of Housing and Urban-Rural Development of the People's Republic of China: Beijing, China, 2011.

26. GB/T 50082-2009; Standard for Test Methods of Long-Term Performance and Durability of Ordinary Concrete. Ministry of Housing and Urban-Rural Development of the People's Republic of China: Beijing, China, 2009.

27. Behfarnia, K.; Rostami, M. An assessment on parameters affecting the carbonation of alkali-activated slag concrete. J. Clean. Prod. 2017, 157, 1-9. [CrossRef]

28. Zhang, L.F.; Han, J.D.; Liu, W.Q.; Wang, S.G.; Han, P. Study on carbonation process of slag cement mortar with large dosage. Bull. Chin. Ceram. Soc. 2015, 34, 591-596.

29. Shi, Z.; Lothenbach, B.; Geiker, M.R.; Kaufmann, J.; Leemann, A.; Ferreiro, S.; Skibsted, J. Experimental studies and thermodynamic modeling of the carbonation of Portland cement, metakaolin and limestone mortars. Cem. Concr. Res. 2016, 88, 60-72. [CrossRef]

30. Shi, Z.G.; Shi, C.J.; Wan, S.; Li, N.; Zhang, Z.H. Effect of alkali dosage and silicate modulus on carbonation of alkali-activated slag mortars. Cem. Concr. Res. 2018, 113, 55-64. [CrossRef]

31. Bakharev, T.; Sanjayan, J.G.; Cheng, Y.B. Resistance of alkali-activated slag concrete to carbonation. Cem. Concr. Res. 2001, 31, 1277-1283. [CrossRef]

32. Puertas, F.; Palacios, M.; Vázquez, T. Carbonation process of alkali-activated slag mortars. J. Mater. Sci. 2006, 41, 3071-3082. [CrossRef] 
33. Pacheco-Torgal, F.; Labrincha, J.A.; Leonelli, C.; Palomo, A.; Chindaprasit, P. Handbook of Alkali-Activated Cements, Mortars and Concretes; Woodhead Publishing: Cambridge, UK, 2014; pp. 319-329.

34. Lange, L.C.; Hills, C.D.; Poole, A.B. The effect of accelerated carbonation on the properties of cement-solidified waste forms. Waste Manag. 1996, 16, 757-763. [CrossRef]

35. Lange, L.C.; Hills, C.D.; Poole, A.B. Effect of carbonation on properties of blended and non-blended cement solidified waste forms. J. Hazard. Mater. 1997, 52, 193-212. [CrossRef]

36. Bernal, S.A. Effect of the activator dose on the compressive strength and accelerated carbonation resistance of alkali silicateactivated slag/metakaolin blended materials. Constr. Build. Mater. 2015, 98, 217-226. [CrossRef]

37. Papadakis, V.G.; Vayenas, C.G.; Fardis, M.N. A reaction engineering approach to the problem of concrete carbonation. Aiche J. 1989, 35, 1639-1650. [CrossRef]

38. Li, S.F. Image Analysis of Cement Microstructure. Master's Thesis, University of Jinan, Jinan, China, 2004.

39. Du, Y.B.; Ge, Y. Effect of metakaolin, glass powder and limestone filler on microstructure and properties of cement paste. J. Build. Mater. 2021.

40. Li, N.; Farzadnia, N.; Shi, C.J. Microstructural changes in alkali-activated slag mortars induced by accelerated carbonation. Cem. Concr. Res. 2017, 100, 214-226. [CrossRef]

41. Rivera, R.A.; Sanjuán, M.Á.; Martín, D.A.; Costafreda, J.L. Performance of ground granulated blast-furnace slag and coal fly ash ternary portland cements exposed to natural carbonation. Materials 2021, 14, 3239. [CrossRef]

42. Groves, G.W.; Brough, A.; Richardson, I.G.; Dobson, C.M. Progressive changes in the structure of hardened C3S cement pastes due to carbonation. J. Am. Ceram. Soc. 1991, 74, 2891-2896. [CrossRef]

43. Zou, R.Z.; Chen, X.T. Kinetic study on carbon dioxide decomposition reaction of ettringite. J. Hebei Inst. Light Chem. Technol. 1991, 1, 42-48. (In Chinese)

44. Grounds, T.; Midgley, H.G.; Novell, D.V. Carbonation of ettringite by atmospheric carbon dioxide. Thermochim. Acta 1988, 135, 347-352. [CrossRef]

45. Hadj-sadok, A.; Kenai, S.; Courard, L.; Darimont, A. Microstructure and durability of mortars modified with medium active blast furnace slag. Constr. Build. Mater. 2011, 25, 1018-1025. [CrossRef]

46. Palacios, M.; Puertas, F. Effect of carbonation on alkali-activated slag paste. J. Am. Ceram. Soc. 2006, 89, 3211-3221. [CrossRef] 